\title{
CONTROLE BIOLŌGICO DE BIOMPHALARIA GLABRATA (SAY, 1818)ATRAVÉS DE TILAPIA NILOTICA (HASSELQUIST, 1757), EM LABORATÓRIO (PULMONATA, PLANORBIDAE. PISCES, CICHLIDAE) '
}

\author{
Roberto Milward de Andrade ${ }^{2}$
}

\begin{abstract}
O peixe ciclideo Tilapia nilotica (Hasselquist, 1757) ( = Sarotherodon niloticus Linnaeus, 1758) foi capaz de impedir o crescimento de 4 populaçóes de 20 espécimens (14-16 $\mathrm{mm}$ de diâmetro) de Biomphalaria glabrata (Say, 1818), mantidas em aquários de vidro, durante cinco semanas, em laboratório.

No Aquário $n^{\circ} 1$ foi introduzido um alevino com $55 \mathrm{~mm}$ de comprimento (não computada a nadadeira caudall: no de no 2, um com $63 \mathrm{~mm}$; no de $n^{\circ} 3$, dois alevinos: com 40 e $46 \mathrm{~mm}$, res. pectivamente; e, finalmente, no de n. 4, três espécimens: com 38,39 e $42 \mathrm{~mm}$, respectivamente.

Os peixes destruiram as desovas dos planorbineos depositadas nas paredes de vidro dos aquários - impedindo, assim, as eclosões e, consequentemente, o aumento das quatro populações em estudo. Reversamente, quando retirados, as populações de planorbineos cresceram em nümero.

Não obstante, salienta-se a necessidade de investigações de campo, afim de avaliar a atividade predatória daquele ciclídeo em condições naturais.
\end{abstract}

\section{INTRODUÇÃO}

O recente interesse pelo incremento - em escalas nacional e internacional - de projetos de estudos destinados ao controle biológico de pragas agrícolas, de vetores de doenças ou de hospedeiros intermediários de parasitos resulta, essencialmente, do reconhecido fracasso na utilização de centenas de substâncias biocidas (inseticidas, etc.), eufemisticamente donominadas "defensi. vos" (sic) pela indústria química multinacional.

Com o espetacular desenvolvimento da ciência química máxime após a II Guerra Mundial, e também com o aumento da demanda de alimentos, foi paralelamente forjada a "dependência" da produção agrícola à- utilização crescente de biocidas: inseticidas, fungicidas, herbicidas, etc

Em consequência, uma verdadeira "sindrome pesticida", alimentada pelo aético objetivo de lucro a todo custo e caracterizada pela utilização maciça de biocidas: clorados, fosforados e carbamatos - segundo o calendário, e não na necessidade de debelar eventuais emergências ou surtos de espécies ditas pragas - foi primeiramente denunciada por Rachel Carson ${ }^{1}$ e, após, cientificamente analisada por numerosos pesquisadores, em diferentes países $2,3,4$.

Historicamente, a aplicação de métodos de controle biológico a espécies indesejáveis à econômia humana é bastante antigo ${ }^{5}$.

Relativamente aos hospedeiros intermediários de diferentes espécies de Schistosoma, a primeira referência associa-se justamente a um peixe: Cyprinus Carpa L., no controle da esquistossomose japônica ${ }^{6}$.

Aquele ciprinóide, autóctone da Ásia Oriental, foi introduzido no Brasil em $1882^{7}$, porém não há informações epidemiológicas específicas relacionadas às numerosas áreas de piscicultura intensiva, paulistas ou de outros estados brasileiros, nas quais a criação de carpa constitui atividade rural importante 8,9

Recente revisão ${ }^{10}$ sobre agentes biológicos no controle de hospedeiros intermediários de Schistosoma mansoni (Sambon, 1907) registra a análise de sessenta artigos científicos nos

1. Apresentado à $30^{a}$. Reunião Anual da Sociedade Brasileira para o Progresso da Ciência (SBPC). São Paulo, SP, 9-15/julho/1978. Realizado com auxilio do CNPq.

2. Centro de Pesquisas "René Rachou" / FIOCRUZ, Belo Horizonte, MG e Universidade Federal de Minas Gerais. 
quais várias espécies ictíicas são assinaladas como predadoras efetivas de planorbineos ou cercariófagas.

Entre os títulos aludidos, quatorze ostentam os nomes de nove espécies malacófagas e urn cercariófaga: Astatoreochromis alluaudi, Astronotus o. ocellatus, Carassium auratus Engraulicypris brevianalis, Haplochromis mellandi, Heteropneustes fossilis, Lepomis microcephalus, Panagasius panagasius, Tilapia melanopleura / = rendalli) e Lebistes reticulatus.

Dois trabalhos sobre cercariofagia de L. reticulatus (Peters, 1859) - pecilideo Cyprinodontiformis, vivíparo e tradicional larvófago - foram desenvolvidos em Puerto Ricol1,12, um na Tailândia ${ }^{13}$ e outro no Brasil ${ }^{14}$.

Em artigo não publicado, Azevedo e cols. ${ }^{15}$ mencionam diferentes especies ictíicas que poderiam ser utilizadas no controle biológico da esquistossomose mansoni.

O controle de Biomphalaria glabrata no Lago da Pampulha (Belo Horizonte, MG) foi, em parte, atribuido à introdução de Tilapia rendalli (Boulenger, 1896) naquele antigo foco de esquistossomose ${ }^{16,17}$.

Investigação experimental, em laboratório, esclareceu o mecanismo de competição entre $T$. rendalli (então denominada melanopleura) e planorbíneos. O peixe, voraz herbívoro, deglute as desovas e os moluscos juvenis junto com a vegetação, mas também os aderidos a suportes imersos. Porém, menos freqr.entemente, a tilápia abocanha espécimens maiores e os devolve intactos, ou tenta decepar-Ihes as antenas, p. ex., quando deslisam no substrato ${ }^{18}$.

$\mathrm{Na}$ Bahia, foi destacada a importância do apaiarí: Astronotus o. ocellatus (Cuv.) - teleósteo onivoro, originário da Bacia Amazónica e introduzido no Nordeste em $1938^{9}$ - no controle de bionfalárias ${ }^{9}$

Novos testes de laboratório $\operatorname{com} A$. o. ocellatus, T. melanopleura (=rendalli), Macropus operculatus, Holostoma timicki e Brachidanio rerio revelaram que as três primeiras atacavam $B$. glabrata: adultas, juvenís e/ou apenas suas desovas $^{20}$.

Os peixes ciclídeos do gênero Tilapia (Smith, 1840) T.(T.)sparrmanii são autóctones da África central. Segundo revisão sistemática de Thys van den Audenaerde ${ }^{21}$, o gênero abrigaria pelo menos 14 subgêneros e 75-80 taxa, entre espécies e subespécies.

Presentemente, encontram-se difundidos na Ásia, no Caribe e na América do Sul. No Brasil, em duras ocasiões diferentes, foram introduzidas três espécies distintas.
A Tilapia (Coptodon) rendalli (Boulenger, 1896) compreende duas subespécies: T. r. swiers trae (Gilchirist e Thompson, 1971) e $T$. $r$. gefuensis (Thyson, 1964). Ignora-se, todavia, qual das duas foi introduzida no Brasil, em 1953, a partir do Zaire, via Amsterdam 22

E dotada de apenas 10 branquiespinas no arco branquial, de hábitos marcadamente fitófa$\operatorname{gos}^{23}$, porém capaz de alimentar-se também de insetos, crustáceos, pequenos moluscos. O intestino é longo e dotado de muitas pregas, ao contrário dos carnívoros que o tem reto e curto. Começa a reproduzir-se com 3-6 meses de idade e pode ovipor 4-6 vezes por ano, originando até seis mil alevinos. Atualmente, constitui significativa fonte de proteinas para populações humanas do Nordeste brasileiro 24,25,26,27,28,29

A espécie Tilapia nilotica (Hasselquist, 1757) foi - juntamente com $T$. (Oreochromis) hornorum (Trewavas, 1966) - foi introduzida no Estado do Ceará a 24-novembro-1971, a partir do lago Bouaké, Cote d'Ivoire (Africa), via Paris, pelo Dr. Jaques Bard, do "Centre Technique Forestier Tropical", França 25,30

O ciclídeo nilotica é planctófago, onívoro. Abaixo do arco branquial, contam-se 23 branquiespinas: característica que limita e determina o tipo de alimento ingerivel ${ }^{31,32,33}$. É espécie menos prolifera que rendalli e, ao contrário desta, incuba os ovos e protege os alevinos na boca $^{26}$.

Admite-se a existência de três subespécies: T. n. nilotica (Hasselquist, 1757), T. n. aduardiana (Boulenger, 1912) e T. n. Cancellata (Nichols, 1923).

Estudos bioquímicos têm sido desenvolvidos no sentido de esclarecer, entre outros, problemas taxonômicos $34,35,36,37,38$.

O cruzamento, com sucesso, de espécies diferentes de tilápia foi realizado na África 39,40 , inclusive entre nilotica fêmea e hornorum macho $^{27}$. Novos dados foram obtidos no Ceará, com produção de $100 \%$ de hibridos machos, férteis - prática destinada a melhorar o rendimento comercial e eliminar o problema da reprodução incontrolada $24,25,30,41,42$

$O$ recente incentivo governamental à piscicultura intensiva e extensiva, o aumento de áreas irrigadas e a sensivel multiplicação de lagos de barragem (alguns dos quais com mais de $1.000 \mathrm{~km}^{2}$ de área inundada: Três Marias, Furnas, Sobradinho e, brevemente, Itaipu), representam, também, possibilidades indiscutiveis de multiplicação de focos de transmissão de esquistossomose em nosso meio - e, ein contrapartida, põe em relevo a necessidade de estudos básicos 
desses novos ecossistemas ${ }^{43,44}$. É de se recordar que somente o Estado de Minas Gerais possui 50 grandes hidrelétricas, incluidas na empresa holding Eletrobrás S/A - porém, quase todas elas permanecem desconhecidas quanto a estudos epidemiológicos de suas populações ribeirinhas; e, também praticamente todas, contam sequer com levantamento limnológico primário, ponto de partida de estudos destinados à . piscicultura extensiva, vale dizer, de produção de alimen$\operatorname{Los}^{45}$.

Justificam-se, ainda, estudos da ictiofauna nativa e alóctone vis-à-vis às populações autóctones de moluscos, com vistas ao controle biológico dos hospedeiros intermediários de $S$. mansoni e ao marejo daqueles ecossistemas, sem os percalços de infecções indesejáveis.

Obviamente, estudos especiais devem merecer as áreas selecionadas para o desenvolvimento de piscicultura intensiva. Assim, o seu fomento e a criação de uma rede complexa de lagoas e açudes, deveria ser precedida, sempre, de levantamentos malacológicos e difusão de ensinamentos profiláticos.

A metodologia adotada no presente trabalho foi análogoa a de investigação anterior ${ }^{18}$, utilizando-se de exemplares de $T$. nilotica descendentes de espécimens procedentes do Estado do Ceará e recentemente introduzidos em tanques escavados no solo, na fazenda experimental da Escola de Veterinária da Universidade Federal de Minas Gerais, em Igarapé, MG.

\section{MATERIAL E MÉTODOS}

O experimento adiante relatado teve duração de dez semanas: 20-dezembro-1977 a 10-março1978, dividida em duas etapas de cinco semanas cada.

1. Aquários - foram utilizados quatro, com armações metálicas e paredes de vidro transparente. Dimensões: $60 \mathrm{~cm}$ de comprimento $X$ $30 \mathrm{~cm}$ de largura $X 30 \mathrm{~cm}$ de altura.

2. Água - proveniente de mina natural, junto ao Lago da Pampulha, Belo Horizonte, MG. Em cada aquário, introduziu-se 28 litros. Ao final da 5. semana: 25/jan., a água de todos os quatro aquários foi trocada, lavando-se convenientemente os recipientes.

3. $p H$ - através de peagômetro, foi determinado a partir de uma pequena amostra retirada de cada aquário, em cinco ocasiões diferentes (Tabela I).

4. Areia - sobre o fundo de vidro de cada aquário, foi colocada areia de rio, lavada, for mando um substrato de cerca de $0,5 \mathrm{~cm}$ de espessura. Quando das trocas de água, a areia foi sempre cuidadosamente examinada e relavada sob torneira.

5. $\mathrm{CaCO}_{3}$ - face à acidez da água de mina, foram colocados em cada aquário 20cc. de $\mathrm{CaCO}_{3}$ pulverulento - que poderia ser, também, utilizado como alimento pelos planorbíneos e pelas tilápias.

6. Alimento - diariamente, foram colocados nos aquários fragmentos de folhas de alface: Lactuca sativa L. As porções anteriormente não utilizadas eram retiradas. Como sói usualmente acontecer nesses ambientes, registrou-se o desenvolvimento de organismos zoo e fitoplanctônicos, que, entretanto, não foram regularmente identificados e também quantificados. Sem embargo, registra-se, aqui, a presença de mais de uma espécie de ciliados (Vorticella sp. e Stylonychia sp., entre outros), oligoquetas, larvas de um psicodideo (PSychoda sp.), copépodos (naup/ii e adultos). ostracodas, rotíferos e algas cloroficeas unicelulares (p. ex., Ankistrodesmus falcatus Ralfs). O desenvolvimento de algas verdes conferia à massa líquida tonalidade perceptivel.

7. Temperaturas, da água e do ambiente (o C) - no primeiro caso, foi determinada com termômetro de mercúrio convencional, diariamente, entre 13 e 14 horas - porém, de um único aquário, tomado como referência. $A$ do ar, foi sempre obtida com termômetro de $M x$. e Mn., à mesma hora.

8. Planorbíneos utilizados - todos os exemplares eram pigmentados e descendiam de outros capturados no Lago da Pampulha, Belo Horizonte, MG. Ao todo, foram utilizados 80 espécimens. Ou seja, 32 com $14 \mathrm{~mm}$ de diâmetro, $32 \mathrm{com} 15 \mathrm{~mm}$ e $16 \mathrm{com} 16 \mathrm{~mm}$, respectivamente. Porém, em cada aquário foram introduzidos e mantidos 20 exemplares: $8 \mathrm{com}$ $14 \mathrm{~mm}, 8 \mathrm{com} 15 \mathrm{~mm}$ e $4 \mathrm{com} 16 \mathrm{~mm}$, respecti. vamente.

9. Mortalidade - quando ocorreu, os espécimens de planorbíneos foram substituidos por outros de iguais dimensões e procedência; isto é, de criação mantida rotineiramente no laboratório (Tabela III).

10.Tilápias utilizadas - sete exemplares de $T$. nilotica, descendentes de individuos introduzidos, a 24-novembro-1971, no Estado do Ceará. Suas dimensões variavam de $38 \mathrm{~mm}$ a $63 \mathrm{~mm}$ de comprimento total. Provieram de tanques existentes na fazenda experimental da Escola de Veterinária/UFMG, Igarapé, MG.

O crescimento alcançado através do tempo: 20-dez.-77 a 25-jan.-78, pode ser apreciado na 
Tabela 2. No caso, estão registradas duas medidas: com e sem a nadadeira caudal.

11. Aumento populacional e crescimento dos planorbineos - Na Tabela 3, estão registrados, por aquário, os números de exemplares introduzidos $(A)$, as alterações dos diâmetros através do tempo (B) e os descendentes da população primitiva, segundo os diâmetros registrados no final do experimento (C). Os dados referem-se, ainda, aos dois períodos considerados, ou seja, quando planorbineos e tilápias estavam associados e quando foram apartados.

12. Marcha dos experimentos - considerandose cada aquário utilizado, procedeu-se da seguinte forma:

a) Aquário 1 - inicialmente, foram introduzidos 20 exemplares de bionfalárias: com $14 \mathrm{~mm}$ (8), $15 \mathrm{~mm}$ (8) e $16 \mathrm{~mm}$ (4), respectivamente.

Durante cinco semanas consecutivas, registrou-se diariamente as desovas depositadas nas paredes de vidro e as que desapareciam, em consequência de eclosões. Com tinta apropriada, desenhava-se um círculo vermetho em torno de cada desova depositada; podendo-se, assim, inversamente, registrar com facilidade o desaparecimento delas.

Ao final do periodo mencionado, redimensionou-se os exemplares pertencentes à população inicial e mediu-se os seus descentedentes (T,abelas 3 e 4$)$. A seguir, introduziu-se um especimen de T.nilotica, cujo comprimento total era de $55 \mathrm{~mm}$ e prosseguiu-se com os registros já nomeados, até completar-se a $10^{\mathrm{a}}$. semana de observações.

b) Aquários 2, 3 e 4 - também em cada um deles, foram introduzidos 20 exemplares de planorbíneos, com diâmetros iguais aos dos mencionados acima. Todas as demais anotaçôes foram análogas.

Porém, ao contrário do primeiro, planorbíneos e tilápias foram introduzidos juntos e assim mantidos durante as cinco primeiras semanas - invertendo-se, entretanto, o modelo da sexta à décima semanas.

No Aquário 2 utilizou-se um único exem. plar de tilápia nilótica, com $63 \mathrm{~mm}$ de comprimento total. No Aquário 3, dois espécimens: com $40 \mathrm{~mm}$ e $46 \mathrm{~mm}$, respectivamente. No Aquário 4, três exemplares: com $38 \mathrm{~mm}, 39 \mathrm{~mm}$ e $42 \mathrm{~mm}$ de comprimento total - excluindo, pois, a nadadeira caudal (Taiselas I a V).

\section{RESULTADOS}

1. $p H$ - através da Tabela I verifica-se que seus valores alteraram-se em função do tempo. Por exemplo, de 5,0 para 6,8 no Aquário 4. $\mathrm{Na}$ verdade, todas as alterações foram no sentido da neutralidade, embora esta não haja sido alcançada em qualquer deles. Assinale-se, ademais, que as moderadas alterações registradas não tornaram o meio incompativel à sobrevivencia dos organismos estudados: peixes e moluscos.

Tabela 1

Valores de $\mathrm{pH}$ das águas dos aquários em que foram realizadas as observações de controle biológico de Biomphalaria glabrata com Tilapia nilotica.

(Belo Horizonte, MG. 20/dezembro/77 a $19 / \mathrm{marcco} / 78$ ).

\begin{tabular}{|c|c|c|c|c|c|}
\hline \multirow{4}{*}{ Aquário } & \multicolumn{5}{|c|}{ Valores de $\mathrm{pH}$, segundo datas* } \\
\hline & \multirow{3}{*}{$\frac{1977}{20 / \text { dez. }}$} & \multicolumn{3}{|c|}{1978} & \multirow{3}{*}{$1 \% / \mathrm{mcoo}^{* *}$} \\
\hline & & \multirow[t]{2}{*}{$6 /$ jan. } & \multicolumn{2}{|c|}{$25 /$ jan. } & \\
\hline & & & 1 & 2 & \\
\hline 1 & 5,2 & 5,6 & 6,8 & 5,4 & 6,7 \\
\hline 2 & 5,9 & 6,0 & 6,8 & 5,8 & 6,4 \\
\hline 3 & 5,6 & 6,1 & 6,8 & 6,1 & 6,6 \\
\hline 4 & 5,0 & 6,1 & 6,8 & 5,9 & 6,4 \\
\hline
\end{tabular}

* Os valores de $\mathrm{pH}$ da coluna 1 refletem as alterações a partir de 20/dez./77. Os da 2, referem-se à água substituida ou nova.

** $\mathrm{pH}$ final das amostras introduzidas em $25 / \mathrm{jan} / 78$ (coluna 2 ). 
2. Temperaturas $(O C)$ - os registros mostraram, nas primeiras cinco semanas, variações de $23^{\circ}$ a $27^{\circ} \mathrm{C}$ para a água, e $21^{\circ}$ para $26^{\circ} \mathrm{C}$ para - ambiente ou ar. Nas cinco últimas, as oscilações foram de $24-27^{\circ} \mathrm{C}$ e $22-28^{\circ} \mathrm{C}$, respectivamente, para a água e para o ambiente (Tabela 4).
3. Crescimento das tilápias - nas condições do experimento, registrou-se crescimento do ciclideo utilizado. Pode-se verificar que, ao cabo das cinco primeiras semanas, o tamanho dos exemplares aumentou de $16 \mathrm{~mm}$ (p. ex., $39-55 \mathrm{~mm}$ ) a $24 \mathrm{~mm}$ (p. ex., $63-87 \mathrm{~mm}$ ), exclusive a nadadeira caudal (Tabela 2 ).

Tabela II

Dimensões dos exemplares de Tilapia nilotica utilizados em 4 aquários, experimentais, com Biomphalaria glabrata.

(Belo Horizonte, MG. 20/dezembro/77 a 1\%/março/78).

\section{Tilapia nilotica}

\begin{tabular}{ccccc} 
Aquário & $\begin{array}{c}\text { Exempia- } \\
\text { resuti } \\
\text { lizados }\end{array}$ & $20 /$ dez. & Biometria (mm) segundo datas \\
\cline { 3 - 4 } 1 & $(1)^{*}$ & & $(55-70)$ & $1 \% /$ março \\
\hline 2 & 1 & $63-82$ & $87-106$ & $78-97$ \\
3 & 1 & $40-52$ & $59-78$ & - \\
& 1 & $46-64$ & $73-93$ & - \\
4 & 1 & $38-54$ & $62-81$ & - \\
& 1 & $39-52$ & $55-70$ & - \\
& 1 & $42-57$ & $65-85$ & - \\
\hline
\end{tabular}

* Exemplar transferido para o Aquário 1, na data indicada.

NOTA: 1) O primeiro dado ( $\mathrm{mm}$ ) refere-se ao comprimento do corpo do peixe; o segundo, inclui também a nadadeira caudal.

2) Em cada aquário, introduziu-se 20 B. g/abrata.

4. Mortalidade - exemplares mortos foram observados nos Aquários 2, 3 e 4 . Ou seja, $20 \%$ (16) do total geral de planorbíneos utiliza. dos. Em todos os casos, foram substituídos por outros de iguais talhes e procedência (Tabela 3).

Todas as tilápias mantiveram-se vivas e com aspecto sadio. Em nenhum caso, observouse comportamento agressivo em relação aos planorbíneos.

5. Crescimento dos Planorbíneos - O crescimento individual dos caramujos ocorreu quer na presença quer na ausência dos ciclídeos. Ao cabo de dez semanas, o exemplar que exibia maior diâmetro media $28 \mathrm{~mm}$. Portanto, no periodo considerado, teve um ganho de pelo menos $12 \mathrm{~mm}$. Quatro outros exemplares alcançaram $27 \mathrm{~mm}$ de diâmetro (Tabela 3 ).
6. Desovas dé planorbíneos, na presenca e na ausência de tilápias - A associação de ambos os organismos não se constituiu em fator impediente à deposição de desovas por parte dos planorbineos. Em outros termos, não foi detectado fenômeno de antibiose. De fato, as bionfalárias desovaram regularmente, quer na presença quer na ausência de um ou mais exem. plares de tilápia nilótica.

Foi, entretanto, observado que, durante a primeira semana (nos Aquários 2, 3 e 4), as desovas depositadas pelos planorbineos permaneceram intocadas. $E$, fato curioso, os ciclídeos mantinham-se na área central dos aquários; portanto, não se aproximavam das paredes de vidro. Aparentemente, essa atitude decorreria de um processo de adaptação às condições do modelo experimental proposto - que encontrava-se num laboratório onde há contínua movimenta- 
ção de pessoas: portanto, com ruídos e projeção de sombras sobre as paredes de vidro.

Durante as cinco semanas em que os quatro aquários utilizados continham tilápias e bionfa- lárias associadas, o número de desovas dos moluscos: depositadas e desaparecidas, e dos novos descendentes $\left(F_{1}\right)$, foi da seguinte ordem:

\begin{tabular}{ccccc}
\hline \multirow{2}{*}{ AQUÁRIO } & \multicolumn{2}{c}{ DESOVAS } & \\
\cline { 2 - 5 } & $\begin{array}{c}\text { Depositadas } \\
\text { Nọ }\end{array}$ & No & $\%$ & $\begin{array}{c}\text { Desaparecidas } \\
\left(\mathrm{F}_{1}\right)\end{array}$ \\
\hline 1 & 390 & 345 & 88,5 & 0 \\
2 & 380 & 289 & 76,1 & 0 \\
3 & 287 & 205 & 71,4 & 0 \\
4 & 413 & 316 & 76,5 & 0 \\
\hline TOT A IS & 1.470 & 1.155 & 78,6 & 0 \\
\hline
\end{tabular}

Registra-se, pois, que o "desaparecimento" de desovas não decorreu de eclosões - o que, obviamente, redundaria no "aparecimento" de descendentes dos 20 exemplares de bionfalárias existentes em cada aquário. $O$ fato è atribuído à atividade predatória das tilápias.

Os dados acima mostram, ainda, que houve maior número de desovas no aquário que continha três tilápias: ou seja, 413 (Aquário 4). Porém, maior número de "desaparecidas" ocorreu num dos aquários com apenas um único espécimen de tilánia: ou seja, 345 (Aquário 1).
No decurso dos experimentos, observou-se, ademais, que numerosas desovas, já prestes a eclodir ou com formas juvenis recém-eclodidas, também desapareciam subitamente - ao que parece, por mostrarem-se mais visíveis aos peixes. De qualquer forma, tratavam-se de desovas que, anteriormente, haviam escapado à caça movida pelos ciclídeos.

Os dados a seguir mostram situação inversa à relatada acima, ou seja, aumento da população primitiva de bionfalárias na ausência de tilápias.

\begin{tabular}{ccccc}
\hline \multirow{2}{*}{ AQUÁRIO } & \multicolumn{4}{c}{ D E SOV A S } \\
\cline { 2 - 5 } & $\begin{array}{c}\text { Depositadas } \\
\text { No }\end{array}$ & Nosaparecidas & $\begin{array}{c}\text { Planorbineos } \\
\left(F_{1}\right)\end{array}$ \\
\hline 1 & 473 & 316 & 66,8 & 53 \\
2 & 592 & 556 & 93,9 & 119 \\
3 & 471 & 466 & 99,4 & 31 \\
4 & 572 & 538 & 94,1 & 140 \\
\hline TOT A IS & 2.108 & 1.876 & 89,8 & 343 \\
\hline
\end{tabular}

De fato, na ausência de tilápias, houve aumento da população inicial em todos os quatro aquários - malgrado a geração $F_{1}$ tenha se mostrado numericamente mediocre: apenas 343 novos individuos, no final de cinco semanas (Tabelas 3 a 6).

Considerando-se o número total de desovas depositadas, nos aquários com e sem tilápias:
3.578 , verifica-se que maior quantidade foi detectada na ausência de tilápias: $58.9 \%$ (2.108). Entre essas últimas, 89,8\% (1.876) "desapareceram" em consequência do processo normal de eclosão.

Também os dados de cada aquário, isoladamente, mostram maior numero de desovas depositadas na ausência de tilápias. Nesses 
Tabela III

População inicial e final de planorbíneos da espécie $B$. glabrata registrada em aquários com e sem Tilapia nilotica.

(Belo Horizonte, MG. 20/Dezembro/77 a 1\%/março/78).

\begin{tabular}{|c|c|c|c|c|c|c|c|c|c|c|c|c|c|}
\hline \multirow{4}{*}{\multicolumn{2}{|c|}{$\begin{array}{l}\text { Diâmetro* } \\
\text { (mm) }\end{array}$}} & \multicolumn{12}{|c|}{ População de planorbíneos, por aquário } \\
\hline & & \multirow{3}{*}{$\begin{array}{c}20 / 12 \\
\mathrm{~s}\end{array}$} & \multicolumn{2}{|l|}{1} & \multicolumn{3}{|c|}{2} & \multicolumn{3}{|c|}{3} & \multicolumn{3}{|c|}{4} \\
\hline & & & $25 / 01$ & $1 \% / 03$ & $20 / 12$ & $25 / 01$ & $1 \% / 03$ & $20 / 12$ & $25 / 01$ & $1 \% / 03$ & $20 / 12$ & $25 / 01$ & $1 \% / 03$ \\
\hline & & & $s$ & c & c & c & $s$ & $\mathrm{c}$ & $\mathrm{c}$ & s & c & c & $\mathrm{s}$ \\
\hline \multirow[t]{4}{*}{ A) } & 14 & 8 & & & 8 & & & 8 & & & 8 & & \\
\hline & 15 & 8 & & & 8 & 1 & & 8 & 2 & & 8 & 2 & \\
\hline & 16 & 4 & & & 4 & 4 & & 4 & 4 & & 4 & 3 & \\
\hline & & 20 & & & 20 & & & 20 & & & 20 & & \\
\hline \multirow[t]{12}{*}{ B) } & 18 & & & 1 & & 6 & & & 9 & 6 & & 6 & 3 \\
\hline & 19 & & 2 & & & 2 & & & & & & & \\
\hline & 20 & & 2 & 2 & & 4 & 5 & & 2 & 3 & & 5 & 4 \\
\hline & 21 & & 3 & & & 3 & & & & & & & \\
\hline & 22 & & 6 & 1 & & & 5 & & 3 & 2 & & 4 & 3 \\
\hline & 23 & & 5 & 4 & & & 3 & & & 2 & & & 2 \\
\hline & 24 & & 1 & 7 & & & 4 & & & 2 & & & 5 \\
\hline & 25 & & 1 & 3 & & & 3 & & & 3 & & & 1 \\
\hline & 26 & & & & & & & & & & & & 1 \\
\hline & 27 & & & 2 & & & & & & 2 & & & \\
\hline & 28 & & & & & & & & & & & & 1 \\
\hline & & & 20 & 20 & & 20 & 20 & & 20 & 20 & & 20 & 20 \\
\hline \multirow[t]{8}{*}{ c) } & $\leqslant 3,0$ & & 24 & & & & 40 & & & 31 & & & 120 \\
\hline & $3.1-$ & 5,0 & 25 & & & & 20 & & & & & & 11 \\
\hline & $5.1-$ & 7,0 & 1 & & & & 26 & & & & & & 2 \\
\hline & $7,1-$ & 9,0 & 1 & & & & 20 & & & & & & \\
\hline & $9,1-$ & 11,0 & 2 & & & & 11 & & & & & & 2 \\
\hline & $11.1-$ & 13,0 & & & & & 2 & & & & & & 4 \\
\hline & $13,1-$ & 15,0 & & & & & & & & & & & 1 \\
\hline & & & 53 & & & & 119 & & & 31 & & & 140 \\
\hline
\end{tabular}

* 14-16mm, em 20/12/77: corresponde à população original de cada aquário.

15-16mm, em 25/01/78: exemplares anteriormente substituídos, em decorrència de mortalidade dos espéciemens originais.

18-28mm, em 25/01 e 1\%/03/78: exemplareas originais, cujos diâmetros assinalados foram atingidos através do tempo.

3 a 16mm, em 25/01 e 1./03: exemplares descendentes da população original, em aquários após a retirada de tilápias.

NOTA: $s=$ sem tilápia; $c=$ com tilápia. 
casos, os percentuais relativos oscilaram de $54,8 \%$ (Aquário 1) a $62,1 \%$ (Aquário 3). (Tabela 6).

Tem-se, pois, que foi impossivel obter aumen- to da população de bionfalárias quando estas estavam associadas a tilápias nilóticas, observando-se fato inverso com a rețirada dos peixes dos quatro aquários utilizados nos experimentos.

Tabela IV

Desovas de Biomphalaria glabrata, depositadas e

desaparecidas (por eclosão e/ou predação), em

aquários com e sem Tilapia nilotica, durante cinco semanas

consecutivas.

(Belo Horizonte, MG. Dezembro/77 a Março/78).

\section{1) Aquário 1}

\begin{tabular}{|c|c|c|c|c|c|c|}
\hline \multirow{2}{*}{ SEMANA } & \multirow{2}{*}{$\begin{array}{l}\text { Periodo } \\
(1977 / 78)\end{array}$} & \multicolumn{3}{|c|}{ TEMPERATURA (OC) } & \multicolumn{2}{|c|}{ DESOVAS } \\
\hline & & Água & & $\mathrm{Ar}$ & $\begin{array}{c}\text { Deposi- } \\
\text { tadas }\end{array}$ & $\begin{array}{l}\text { Desapa- } \\
\text { recidas }\end{array}$ \\
\hline \multicolumn{7}{|l|}{ A) Sem Tilápia } \\
\hline 1 & $20 / 12-27 / 12$ & $23-25$ & 21 & -26 & 84 & 0 \\
\hline 2 & $28 / 12-3 / 01$ & $23-26$ & 22 & -25 & 124 & 22 \\
\hline 3 & $4 / 01-10 / 01$ & $24-25$ & 24,5 & -26 & 75 & 90 \\
\hline 4 & $11 / 01-17 / 01$ & $23-24,5$ & 22 & -25 & 119 & 101 \\
\hline 5 & $18 / 01-24 / 01$ & $24-27$ & 2,5 & -26 & 71 & 103 \\
\hline- & - & $23-27$ & 21 & -26 & 473 & 316 \\
\hline
\end{tabular}

B) Com Tilápia

$\begin{array}{rlrrrrrr}6 & 25 / 01-31 / 01 & 25 & -27 & 25-28 & 57 & 47 \\ 7 & 19 / 01-8 / 02 & 26 & -26 & 26 & -27 & 79 & 60 \\ 8 & 9 / 02-15 / 02 & 24 & -26 & 22,5-27 & 102 & 77 \\ 9 & 16 / 02-22 / 02 & 24 & -25 & 22 & -26 & 68 & 72 \\ 10 & 23 / 02-19 / 03 & 24,5-25 & 23-26 & 84 & 89 \\ - & - & 24-27 & 22-28 & 390 & 345\end{array}$

* Em decorrência da eclosão dos ovos e/ou predação das desovas, pelo exemplar de Tilapia nilotica introduzido, na 6a semana.

**Biometria do exemplar: (1) comprimento inicial $=55.70 \mathrm{~mm}$; (2) comprimento no final do experimento $=78-97 \mathrm{~mm}$ (i.e., com e sem inclusão da nadadeira caudal). 
Tabela $V$

Desovas de Biomphalaria glabrata, depositadas e desaparecidas (por eclosão e/ou predação), em aquários com e sem Tilapia nilotica, durante dez semanas consecutivas.

(Belo Horizonte, MG. Dezembro/1977 a Março/1978).

\begin{tabular}{|c|c|c|c|c|c|c|}
\hline \multirow{3}{*}{ Semana } & \multicolumn{4}{|c|}{ Desovas, depositadas e desaparecidas * } & & \\
\hline & \multicolumn{2}{|c|}{$\begin{array}{c}\text { Aquário } 2 \\
\text { (c/1) }\end{array}$} & \multicolumn{2}{|c|}{$\begin{array}{c}\text { Aquário } 3 \\
(\mathrm{c} / 2)\end{array}$} & \multicolumn{2}{|c|}{$\begin{array}{c}\text { Aquário } 4 \\
(\mathrm{c} / 3)\end{array}$} \\
\hline & Dp. & Dd. & Dp. & Dd. & Dp. & Dd. \\
\hline
\end{tabular}

A) Com tilápias

\begin{tabular}{|c|c|c|c|c|c|c|}
\hline 1 & 50 & 0 & 78 & 0 & 54 & 0 \\
\hline 2 & 57 & 16 & 50 & 128 & 71 & 113 \\
\hline 3 & 56 & 61 & 17 & 3 & 101 & 44 \\
\hline 4 & 128 & 78 & 88 & 21 & 128 & 50 \\
\hline 5 & 89 & 134 & 54 & 53 & 59 & 109 \\
\hline TOTAIS & 380 & 289 & 287 & 205 & 413 & 316 \\
\hline
\end{tabular}

B) Sem tilápias

$\begin{array}{rrrrrrrr}6 & 153 & 105 & 100 & 111 & 98 & 79 \\ 7 & 124 & 165 & 62 & 64 & 119 & 64 \\ 8 & 107 & 102 & 118 & 72 & 142 & 128 \\ 9 & 94 & 92 & 93 & 104 & 133 & 123 & 144 \\ 10 & 114 & 92 & 98 & 115 & 80 & 538\end{array}$

* Entre parêntesis, as quantidades de exemplares de tilápias utilizadas em cada aquário indicado, os quais abrigavam, cada um, 20 exemplares de $B$. glabrata $(8 \mathrm{c} / 14,8 \mathrm{c} / 15 \mathrm{e} 4 \mathrm{c} / 16 \mathrm{~mm}$ de diâmetro). $\mathrm{Dp}=$ depositadas. $\mathrm{Dd}=$ desaparecidas (em consequência de eclosão e/ou predação).

NOTA: Os períodos (datas) e temperaturas (água e ar) correspondentes a cada semana são os mesmos indicados na Tabela

\section{DISCUSSÃO}

$O$ incremento atual da piscicultura intensiva e extensiva - respectivamente, pois, em pequenas (lagoas, açudes, etc.) e volumosas (lagos) massas d'água - põe de manifesto a necessidade de medidas acauteladoras destinadas a minimizar a inevitável expansão de ecossistemas apropriados às populações de vetores, transmissores e/ou hospedeiros intermediários de parasitos.

Se é verdade que, no Brasil, não há registro de acontecimentos desastrosos consequentes à construção de barragens - como, p. ex., os que perduram na África, junto aos grandes lagos artificiais de Kariba, Volta, Kainji, etc. ${ }^{46}$ - nem por isso seriam válidas atitudes exageradamente otimistas. Pois, com o contínuo aumento populaciónal e a progressiva ocupação humana de áreas próximas ou imediatamente adjacentes aos lagos artificiais, fácil será a instalação de importantes focos de transmissão, p. ex., de esquistossomose mansoni. Como áreas particularmente propícias, vale lembrar os campos irrigados.

Assim, será oportuno o desenvolvimento de projetos de pesquisas ictíicas relacionados à malacofauna regional e, em particular, aos hospedeiros intermediários do Schistosoma 
Tabela VI

Desovas de Biomphalaria glabrata, depositadas e desaparecidas (por eclosão e/ou predação), em aquários com e sem exemplares de Tilapia nilotica.

(Belo Horizonte, MG. Dezembro/1977 a Março/1978).

\begin{tabular}{|c|c|c|c|c|c|c|c|c|c|c|}
\hline \multirow{3}{*}{ DADOS } & \multicolumn{10}{|c|}{ № de desovas de caramujos, segundo os aquários * } \\
\hline & \multicolumn{2}{|r|}{1} & \multicolumn{2}{|r|}{2} & \multicolumn{2}{|r|}{3} & \multicolumn{2}{|r|}{4} & \multicolumn{2}{|c|}{ TOTAIS } \\
\hline & Depos. & Desap. & Depos. & Desap. & Depos. & Desap. & Depos. & Desap. & $\begin{array}{c}\text { Depo- } \\
\text { sit. }\end{array}$ & $\begin{array}{l}\text { Desa- } \\
\text { par. }\end{array}$ \\
\hline Sem tilápia & 473 & 316 & 592 & 556 & 471 & 466 & 572 & 538 & 2.108 & 1.876 \\
\hline Com 1 tilápia & 390 & 345 & 380 & 289 & - & - & - & - & 770 & 634 \\
\hline Com 2 tilápias & - & - & - & - & 287 & 205 & - & - & 287 & 205 \\
\hline Com 3 tilápias & - & - & - & - & & - & 413 & 316 & 413 & 316 \\
\hline $\begin{array}{l}\text { TOTAIS } \\
\%:\end{array}$ & 863 & 661 & 972 & 845 & 758 & 876 & 985 & 854 & 3.468 & 3.031 \\
\hline Sem tilápia & 54,8 & - & 60,9 & - & 62,1 & - & 58,1 & - & 58,9 & - \\
\hline Com tilápia & 45,2 & - & 39,1 & - & 37,9 & - & 41,9 & - & 41,1 & - \\
\hline
\end{tabular}

* Desovas postas por 20 exemplares $(8 \mathrm{c} / 14 \mathrm{~mm} ; 8 \mathrm{c} / 15 \mathrm{~mm} ; 4 \mathrm{c} / 16 \mathrm{~mm})$ de $B$. g/abrata, mantidos em cada aquário e alimentados com alface fresca.

Depos. = depositadas. Desap. = desaparecidas (em decorrência de eclosão e/ou predação pelas tilápias).

mansoni, em nosso meio.

De fato, o melhor conhecimento de espécies malacófagas poderá traduzir-se na sua utilização em piscicultura, quer como fornecedora, ela mesma, de proteinas, quer, adicionalmente, como agente de controle biológico de planorbineos consequentemente, de esquistossomose mansoni.

Situação dessa ordem é a que deverá prevalecer em tanques, açudes e lagoas em que se criem Tilapia rendalli - posto que, experimentalmente e também na prática, tem se revelado eficiente predador de planorbíneos, destruindo os ovos e as formas juvenís ${ }^{17,20}$.

A introdução mais recente de dcis outros cíclídeos: Tilapia nilotica e $T$. hornorum - que, ao que parece, deverão ter preeminência sobre rendalli - justificam observações bioecológicas análogas às anteriormente mencionadas. Em outros termos, que se conheçam adequadamente seu comportamento - de alevino à fase adulta face às diferentes etapas evolutivas de bionfalárias. Modelos experimentais de campo e laboratório são extraordinariamente desejáveis e, mesmo, indispensáveis.

O experimento preliminar relatado revelou que a espécie $T$. nilotica, reconhecidamente planctófaga, impediu o crescimento de populações de bionfalárias mantidas em aquários, em laboratório.

Sem embargo, são necessárias novas observações, muito particularmente no campo - posto que o comportamento em ambientes estreitos, confinados nem sempre são extrapoláveis.

Em especial, no caso, deve-se lembrar que a espécie mencionada, segundo autores, é micrófaga. Dessa forma, restaria também verificar se, na natureza - face a ampla disponibilidade de alimentos: zoo e fitoplantônico - repetiria atividade predatória em relação a desovas de planorbíneos depositadas em suportes imersos.

Em seguimento às investigações relatadas, desenvolvem-se, no Laboratório de Ecologia/ CPqRR, novos projetos - considerando-se, inclusive, a espécie $T$. hornorum e os híbridos machos resultantes de seu cruzamento com Tilapia nilotica.

Do ponto de vista operacional e logístico, pesquisas tecnológicas e básicas seriam talvez melhor realizadas através de dinâmica interação de organismos que têm pontos afins, tais como: Fundação Oswaldo Cruz (FIOCRUZ), Instituto Nacional de Alimentação e Nutrição (INAN), 
Superintendência de Desenvolvimento da Pesca (SUDEPE), Empresa Brasileira de Pesquisas Agropecuárias (EMBRAPA) e Universidades Federais, Estaduais e privadas - o que, certa. mente, poderia apressar e ampliar aqueles conhecimentos reclamados pelo setor. Isto é, atendimento das profundas necessidades nutricionais e alimentares de extensa parcela da popu. lação nacional sem criar, inadvertidamente, novas áreas de transmissão de parasitoses - todas elas, ecologicamente controláveis.

\section{SUMMARY}

Cichlid fish from the genus Tilapia nilotica (Hasselquist, 1757) (= Sarotherodon niloticus Linnaeus, 1758) could hinder the increase of four Biomphalaria glabrata (Say, 1818) populations of 20 specimens (14-16mm diameter) kept in glass aquaria containing 28 liters of fresh water, during five weeks, in the laboratory.

In aquarium n? 1, was introduced one alevin $55 \mathrm{~mm}$ long (not computed to the caudal fin); in n? 2, one $63 \mathrm{~mm}$; in n? 3, two alevins: 40 and $46 \mathrm{~mm}$; and, finally, in aquarium $n$ ? 4 , three specimens with 38,39 and $42 \mathrm{~mm}$, respectively.

The fish ate the planorbid spawnings laid on the aquarium walls - thus hindering the eclosion of the snail's eggs and therefore, the consequent increase of the four mollusc populations under experiment.

With the removal of the alevins, it was observed that the planorbid populations increased in the next five weeks.

There is a necessity for field investigations to evaluate the predatory action of cichlid fish in natural conditions.

\section{REFERẼNCIAS BIBLIOGRÁFICAS}

1. CARSON, R. Silent spring. 368pp.; Honghton Mifflin Co., Bosturi, 1962.

2. DOUTT, R.L. \&SMITH, R.F. The pesticide syndrome - diagnosis and suggested prophylaxis. In: Biological Control, pp. 3-15, 1971, Huffaker, C.B., op. cit, 1971.

3. HUFFAKER, C.B. (Ed.) Biological Control. 511 pp.; Plenum Press, New York 1971.

4. DeBACH, P. Biological Control by Natural Enemies. 323pp;Cambridge Univ. Press, London, 1974.
5. ARAGÃO, M.B. Equilíbrio da natureza e controle biológico . Rev. Brasil. Malariol. D. Trop. 19:655-95, 1967.

6. YUKI, G. The intermediate host of Schistossoma japonicum and the carp. Kyoto Igakkai Z.J. Kyoto Med. Ass., 16(12), 1919.

7. GODOY, M.P. Carpas e tilápias. Chácaras \& Quintais, 111: 177-80/1965.

8. CRUZ, A.M. Alguns capítulos para a história da piscicultura no Estado de São Paulo. Bol. Ind. Animal, São Paulo, 6:174-79. In: Nomura, H., 1975, op. cit., 1943.

9. NOMURA, H. Desenvolvimento atual e perspectivas da piscicultura intensiva e extensiva no Estado de São Paulo. Annais 1 Enc. Nac. Limnologia, Piscicultura e Pesca Continental, pp. 259-76. Secretaria Planejamento e Coordenação Geral, Fundação João Pinheiro, Belo Horizonte, 1975.

10. FERGUSON, F.F. The Role of Biological Agents in the Control of SchistosomeBearing Snails. 107pp., US. Dept. Hith., Educ. \&Welf., Publ. HIth. Serv., Atlanta, 1977.

11. OLIVER-GONZALEZ,J. The possible role of the guppy, Lebistes reticulatus, on the biological control of Schistosoma mansoni. Science, 104 (2712) : 605, 1946.

12. KNIGHT, W.B.; RITCHE, L.S. \& CHIRIBOGA, J. Cercariophagic activity of guppy fish (Lebistes reticulatus) as manifested by radioactivity following feeding of cercariae labelled with radioselenium $(75 \mathrm{Se})$. Ann. Meeting Am. Soc. Trop. Med. Hyg. \&Am. Soc. Parasit. Washigton, 1969.

13. ChESPADEN, C.; KRUATRACHUE, M. \& HARINASUTA, C. The predatory activity of the guppy fish (Lebistes reticulatus) to Schistosoma spindale cercariae. J. Med. Ass. Thailand, 49:946-949, 1966.

14. PELLEGRINO, J.; MARIA, M. \& MOURA, M.F. Observations on the predatory activity of Lebistes reticulatus (Peters, 1859) on cercariae of Schistosoma mansoni. 
Am. J. Trop. Med. Hyg., 15: 337-341, 1966.

15. AZEVEDO,P.; ALCKMIN, G.J.R.; MALDONADO, J.M; VAZ, J.O.; PARREIRAS, W.B. \& ROJAS, J.T. Peixes como auxiliares de combate à esquistossomose. 23pp. datilografadas. Apresentado ao Depto. Produção Animal, Min. Agricultura e à Soc. Brasileira de Zoote. cnia, em 30/maio/1960. (Não publicado).

16. MILWARD-DE-ANDRADE, R. O problema da esquistossomose mansoni no Lago artificial da Pampulha, Belo Horizonte, Minas Gerais (Brasil). Rev. Brasil. Malariol. D. Trop., $11: 653-74,1959$.

17. MILWARD-DE-ANDRADE, R. Nota ecológica sobre o Lago da Pampulha (Belo Horizonte, MG), com especial referência aos planorbídeos. Rev. Brasil. Malariol. D. Trop., $21: 59-116,1969$.

18. MILWARD-DE-ANDRADE, R. \&ANTUNES, C.M.F. Combate biológico: Tilapia melanopleura Duméril versus Biomphalaria glabrata (Say), em condições de laboratório Rev. Brasil. Malariol. D. Trop., 21 : $49-58,1969$.

19. MOTTA, J.G. \& GOUVÉA, J.A.G. Utilização de Astronotus ocellatus ocellatus no controle biológico de Biomphalaria glabrata. Gaz. Méd. Bahia, 71:55-58, 1971.

20. GOUVÊA, J.A.V. \& MOTTA, J.G. Capacicidade malacófaga de alguns peixes. Gaz. Méd. Bahia, 71 : 52-54, 1971.

21. THYS van den AUDENAERDE, D.F.E. Ann Annoted Bibliography of Tilapia (pisces, Cichlidae). 406pp.; Mus. Roy. de I'Afrique Centrale, Tervuren. Doc. Zool., n? 4, 1968.

22. AZEVEDO, P. Aclimação da tilápia no Brasil. Chácaras \& Quintais 92:190-92. 1955.

23. MANN, $H$. The utilization of food by Tilapia melanopleura, Dum. FAO Fish Report, 44:408-410, 1967.

24. BARD, J. Piscicultura Intensiva no Estado .do Ceará. 65pp.; Min. Interior/DNOCS,
Fortaleza \& Centre Technique Forrestier Tropical, Nogent-sur-Marne, France, 1973.

25. BARD, J. Piscicultura intensiva e extensiva nas regiões tropicais. Fundamentos limnológicos de seu desenvolvimento racional. Anais I Enc. Nac. Limnologia, Piscicultura e Pesca Continental, 108-134. Secretaria Planejamento e Coordenação Geral, Fundação João Pinheiro, Belo Horizonte, 1975.

26. BARD, J. Los peces de piscicultura intensiva en la America Tropical. El problema de los peces exoticos. Notes et Documents (Nouv.Sér.) 12:31 - 49, 1976.

27. BARD, J. \& LEMASSON, J. Nouveau poissons et nouveau systèmes pour la pisciculture en Afrique. Proc. World Symp. Warm-Water Pond Fish Cult., Rome. FAO Fish. Report, 5:182-195, 1968.

28. BARD, J.; LEMASSON, J. \& LESSENT, P. Manual de Piscicultura destinado a la America Latina. 139pp.; Centre Technique Forrestier Tropical, Nogentsur-Mane, France, 1970.

29. PAIVA, M.P. \&GeSTEIRA, T.C.V. Produtividade da pesca nos principais açudes públicos do Nordeste do Brasil. Notes et Documents (Nouv. Sér.), 14:55-67, 1977.

30. SILVA, A.B.; SOBRINHO, A.C.; FERNANDES, J.A. \& LOVSHIN, L.L. Observations préliminaires sur l'obtention d'hybrides tous mâles des espèces Tilapia hornorum et Tilapia nilotica. Notes et Documents (Nouv. Sér.), 7:1-8, 1973.

31. Planquette, P. \& Petel, C. Quelques données sur la valeur nutritive de certains produits utilisés comme aliments pour l,élevage intensif de Tilapia nilotica. Notes et Documents Pêche Pisc., (Nouv. Sér.). 12:21-29, 1976.

32. PlanquetTe, P. \& PETEl, C. - Données sur la production en masse d'alevins de Tilapia nilotica. Notes et Documents Pêche Pisc. (Nouv. Sér.), 14: 1-6, 1977.

33. PlanQueTte, P. \& PETEL, C. Deuxième note sur la valeur nutritive de certains produits utilisés comme aliments por 
l'élevage intensif de Tilapia nilotica. Notes et Documents Pêche Pisc., (Nouv. Sér.), 14:35-42, 1977.

34. ILES, T.D. \& HOWLETT, C.J. Electrophoretic analysis of blood of Tilapia leucostica Trewavas and Tilapia zillii (Gervais) from Lake Victoria. East Afr. Freshw. Fish. Res. Org., Annual Report for 1967, pp. 64-72, 1967.

35. CHEN, F.Y. \&TSUYUKI, H. Zone electrophoretic studies on the proteins of Tilapia mossambica and hornorum and their $F_{1}$ hybrids, T. zillii and $T$. melanopleura. J. Fish. Res. Bd. Canada 27:2167-77, 1970.

36. BADAWI, H.K. Eletrophoretic studies of serum proteins of four Tilapia species (Pisces). Marine Biology, 8: 96-98, 1971 a.

37. BADAWI, H.K. A comparative study of the blood of four Tilapia species (Pisces). Marine Biology, 8:202-204, 1971b.

38. BARON, J. C. Note sur le sérum de 4 epèces de Tilapia: Tilapia mossambica Peters, 1852, T. nilotica (Linnaeus, 1758), T. zilii (Gervais, 1848) et T. Macrochir Boulenger, 1912. Cah. O.R. S.T.O.M., sér. Hydrobiol. 9: 19-24, 1975.

39. PRUGINING, Y. The culture of carp and tilapia hybrids in Uganda. Proc. World Symp. Warm-Water Pond Fish Cult., Rome. FAO Fish. Report, 4:223-229, 1968.

40. HICKLING, C.F. Fish-hybridization. Proc. World Symp. Warm-Water Pond Fish Cult., Rome. FAO Fish. Report., 4:1-11, 1968.
41. LOVSHIN, L.; PEIXOTO, J.T. \&VASCON CELOS, E.A. Considerações ecológicas e econômicas sobre Tilapia sp. no Nordeste brasileiro. Anais I Enc. Nac. Limnologia, Piscicultura e Pesca Continental, pp. 227-237. Secretaria Planejamento e Coordenação Geral, Fundação João Pinheiro, Belo Horizonte, 1975.

42. LOVSHIN, L. et alii. Intensive culture of the all male hybrid of Tilapia hornorum (male) X Tilapia nilotica (female) in Northest Brazil. 18pp., FAO/CARPAS Symp. on Aquacult. Latin America. Montevideo, 1975.

43. BONETTO, A.A. A Limnologia como fundamento da exploração racional da pesca continental. Anais I Enc. Nac. Limnologia, Piscicultura e Pesca Continental, pp. 31-51. Secretaria Planejamento e Coordenação Geral, Fundação João Pinheiro, Belo Horizonte, 1975.

44. LAURENT, P. O papel dos Institutos de Limnologia e Ecologia Aplicada na exploração regional dos recursos naturais renováveis. Anais I Enc. Nac. Limnologia, Piscicultura e Pesca Continental, pp. 53-62. Secretaria Planejamento e Coordenação Geral, Fundação João Pinheiro, Belo Horizonte, 1975

45. MILWARD-DE-ANDRADE, R. Situação atual da Limnologia, Piscicultura e Pesca Continental no Estado de Minas Gerais (1975). Annais I Enc. Nac. Limnologia, Piscicultura e Pesca Continental, pp. 387-400. Secretaria Planejamento e Coordenação Geral, Fundação João Pinheiro, Belo Horizonte, 1975.

46. STANLEY, N.F. \& ALPERS, M.P. (Ed.) Man-Made Lakes and Human Health. 495pp.; Academic Press, London, N.Y., San francisco, 1975. 